\title{
Research of Computer Assisted English Teaching Based on Corpus LI Liang ${ }^{1, a}$ \\ ${ }^{1}$ Foreign Language School, Wuhan Polytechnic, Wuhan 430074, P.R China \\ aliliang109@126.com
}

Keywords: Corpus, computer-assisted, English teaching

\begin{abstract}
In the present English teaching and English learning, computer-assisted language learning mode has become a way to comply with the requirements of the information age learning. All kinds of teaching software and learning system, through the use of advanced technology, will vocabulary learning content and a lot of pictures, text, audio and video data. Students in learning vocabulary, text, sound, like, you can choose according to their own specific situation learning content and way, such not only can stimulate learners' interest, improve the efficiency and quality of vocabulary learning, also can cultivate learners' autonomous learning ability.
\end{abstract}

\section{The brief introduction of corpus}

Corpus is a language according to certain principles, applying the method of random sampling, collecting naturally occurring language in a row. It uses text or discourse to build a large electronic text library with quite big capacity. From its essence, corpus is actually random sampling on the use of the natural language, and a certain size of language sample represents the general application of language in one study. On the other hand, corpus linguistics, based on the corpus, objectively describes English, and the research of which is the application of language called performance, rather than language skills (competence). Therefore, "corpus linguistics" is not a new subject, but a new study method, with real language data as the research object, analyzing a large number of language facts from the macroscopic Angle, and finding the rule of language in it. It adopts probability method in the analysis of languages, with actual use of language phenomenon the emergence of probability based on an analysis of the various aspects of the language. As the language materials in the corpus are the practical application of language in reality, therefore, the research results of corpus linguistics has the reliability and authenticity.

The development of corpus linguistics has roughly experienced three stages: the first stage, from the early 18 th century to the $1950 \mathrm{~s}$; the second stage, from the $1960 \mathrm{~s}$ to so $1980 \mathrm{~s}$; the third stage, from 1980s till now. The first stage belongs to the early development of corpus, and is the development period of all kinds of manual corpus before the appearance of computer corpus. Although the corpus collected by hand is very little, sample representativeness is not strong, and the corpus processing and analysis work is voluminous, early corpus still plays an important role in the following areas: the bible and literature research, dictionary compiling, dialect research, the study of language education. Because of the rapid development of computer technology, the second phase of construction of corpus has the main characteristics with the rise of electronic corpus. The capacity of corpus increases and the species grows in this phase. In the third stage, corpus has rapid development, the species increases greatly, which helps people research more deeply, and corpus is widely applied to various fields related to language.

\section{The computer-assisted English teaching}

Computer entering into the teaching area is a huge impact on traditional teaching forms and teaching methods. We know that, for so many centuries, our teaching is in the "collective listening class" under the traditional teaching form, causes both teaching and learning certain blindness. Computer-assisted instruction can arrange teaching flexibly and give full play to students' study enthusiasm. Each student sit in front of a terminal or a badge machine, as in the face of their own "private teacher", through the human-computer interaction, the formation of "one to one" teaching 
system. Students can choose the most convenient time, arrange the most suitable learning progress, and learn different content from their own "private teacher" according to your own needs. When faced with difficulties, they can slow down to complement, and do more practice; when feel easy after computer test is qualified, they can speed up the process or do less exercises.

Computer aided English teaching software face to students is roughly divided into the following four categories:

(1) Programmed Learning

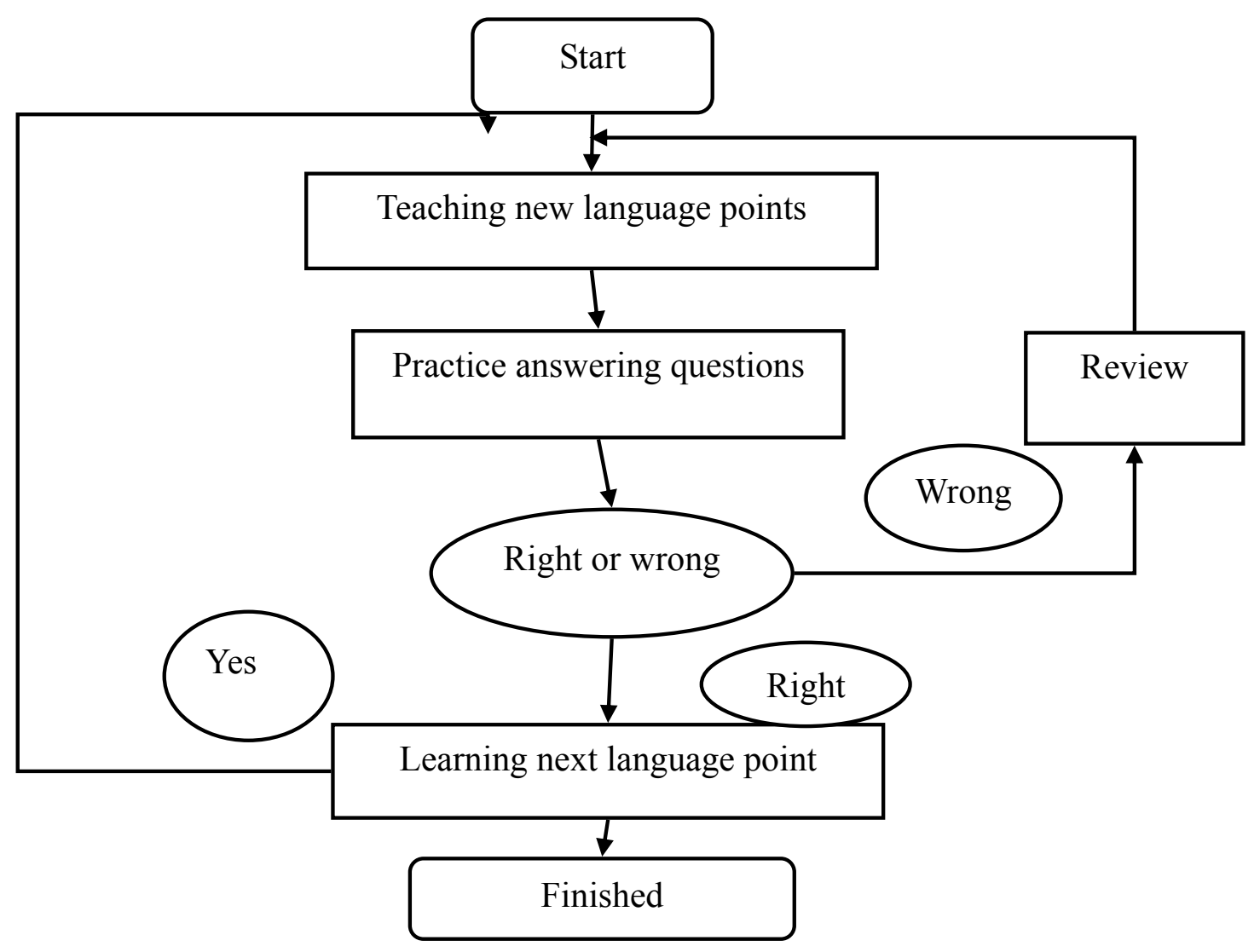

Chart 1: Linear program flow chart

Programmed learning is the earliest form that is adopted by computer aided teaching. It is first appeared in the United States and then spread to Western Europe, the Soviet Union. Compared with the conventional textbooks, the advantage of using computer teaching program is obvious. Decomposition of language teachers teaching content and arrangement of teaching process, in addition to the analysis to study the nature of language, it also gives full consideration to the level of the students, the study purpose and the regularity of language teaching and other factors. This is the key to a successful program teaching. In the division of language points and teaching, review, practice and test and consolidate the teaching links such as clear and detailed provisions, it will set strict teaching process like chart 1 :

(2) Practice and test

Practice is one of the practical major means for students to master a foreign language. Every foreign language learners do thousands of exercises in the process of learning because they can only gradually form language skill through mass of practice to practice. As the famous language scholar Bloomfield says that learning a language is to practice, practice, there is no usage of other methods. Typical practice program flow chart is as following chart 2: 


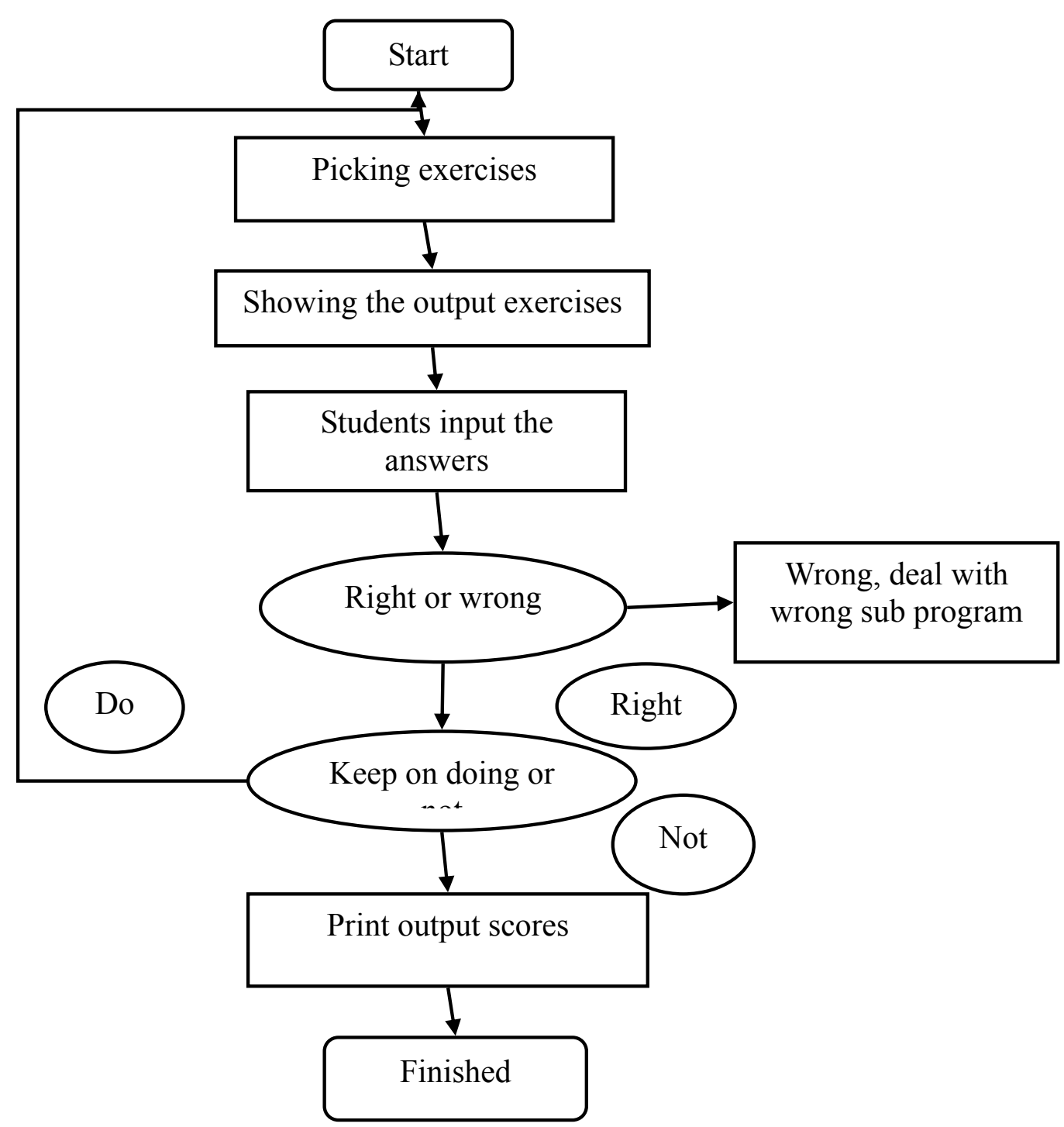

Chart 2: practice program flow chart

\section{The application of computer corpus in the English teaching}

\section{Application of computer corpus in the English vocabulary teaching}

With the introduction of corpus linguistics, corpus is widely applied in the areas of language teaching and research, which shows strong vitality and broad prospects for development. From present application and research of corpus, the study of vocabulary is the most active aspect. Vocabulary study based on corpus has made a remarkable achievement, makes people increasingly realize the importance of vocabulary teaching which cannot be replaced. Although we have large corpus resources, if you want to apply these resources to vocabulary teaching, we also need to use some corpus indexing software to help us get the needed information. Common corpus retrieval search engines are WordSmith, kfNgram, AntConc and so on. the Basic function of indexing software includes word-generated, discourse statistics, context of keywords (KWIC) index, sorting, statistical word type, subject headings, collocation of words extraction, word cluster statistical word, thinking and restructuring words, and the word figure statistics and restructuring. In the foreign language teaching, the application of index corpus in vocabulary teaching and learning has the following several aspects:

(1) The corpus index can provide true information about the usage and meaning, and to check explanation and illustration from dictionary or provided in the textbook. Through index, learners can experience the exact use of words or phrases in different contexts, to increase the perceptual 
knowledge.

(2) A synonym for comparison. Corpus index can provide abundant usage and context to synonym group, enable learners to compare and grasp the subtle semantic pragmatic differences between synonyms.

(3) The word collocation. Corpus index provides the information and usage of lexical collocation. Usually, problems cannot make sure that teachers can solve easily.

(4) Preparation of instant classroom practice. Most index software provides the contract word covered (Zapping) function, makes the teacher use the index to easily fill in the blanks in practice.

\section{English teaching assisted by corpus}

Form the following chart 3 we can know that the English teaching assisted by corpus has the following process:

1) Students select research subjects under the guidance of teachers according to the course content and their interest. At the same time, teachers should teach basic corpus retrieval methods so that set the stage for the subsequent courses and activities;

2) Students can set a thoughtful study plan through group discussion and suggestions of teachers, and this plan will make students' learning activities carried out according to the can depend on, causes the student to understand the general research process;

3) Exploring activities through the use of all kinds of books and reference books, computer network, collecting and reading literature, at the same time taking the questionnaire survey, interview, field investigation, collecting data and using the relevant statistical software for data analysis and discussion.

4) Daily classroom display is conducted with activity exploring. It is also a chance for students to get language output through multimedia, each group of students needs to report the project progress to their guiding teachers and other groups through the daily classroom display.

5) Project report writing. Students summarize their research topics in the form of a research report.

6) Project evaluation are done by teachers, peer and learners themselves.

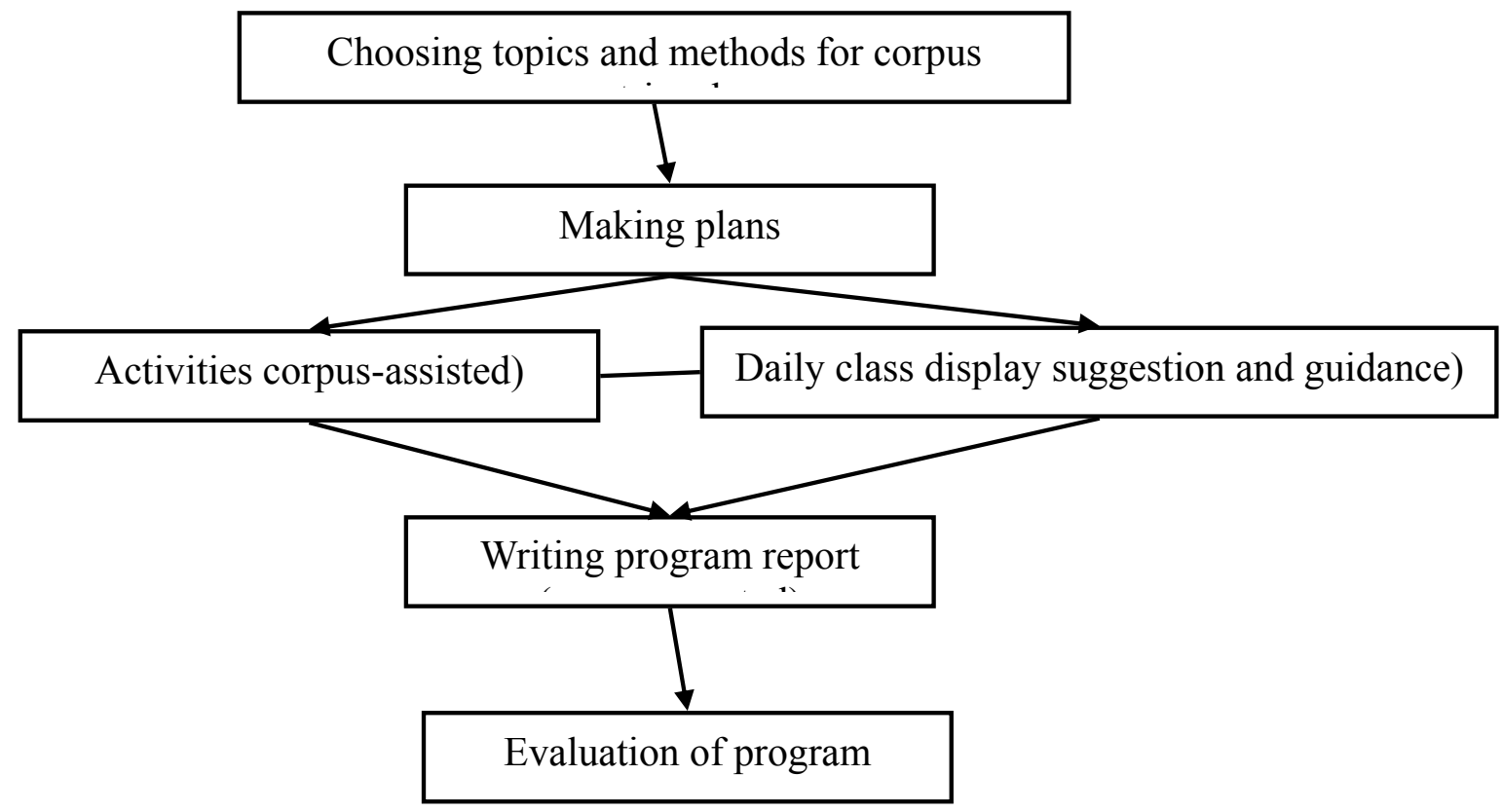

Chart 3: English teaching mode assisted by corpus

\section{Summary}

Using computer-assisted corpus to help vocabulary teaching is not only good for setting teaching content and sequence arrangement, and also improving the students' learning enthusiasm and autonomous learning ability, adapting to the trend of the development of the language teaching. 
Computer assisted language learning is now one of the most important symbols of reform of foreign language teaching. On English vocabulary learning, we should make full use of modern teaching means to display and use of more information. On the basis of in accord with learners' understanding of the process, they should actively create a more ideal learning environment and improve the efficiency of vocabulary memory and learners' autonomous learning ability. Future more, the more development and use of interactive software will provide a broader space for computer aided English vocabulary teaching.

\section{References}

[1] Jiang Ping, Sun Xiaoyan, Xu Xuemei, Experimenting Corpus-Assisted Instruction in Teaching Essentials of English in EFL Context. Education Research monthly,2013(12):81-86.

[2] Sinclair, J. M. Corpus, Concordance, and Collocation [M].Oxford: Oxford University Press, 1991.

[3] Biber, D., S. Conrad, \& R. Reppen. Corpus linguistics: Investigating language structure and use [M]. Cambridge: Cambridge University Press, 1998.

[4] Wood D, Bruner J Soss G. The Role of Tutoring in Problem Solving [J]. Journal of Child Psycho logy and Psychiatry,1976, (17): 89 100.

[5] Liu T K E, Shaw M P. Investigating L earner Vocabulary: A Possible Approach to Looking at EFL /ESL Learners 'Qualitative K now ledge of the Word[J] . IRAL, 2001, (39): 171-194 